\title{
A Review on Heteroaryl Substituted Pyrazolines with their Pharmacological Activity and SAR Studies
}

\author{
Anatt Treesa Mathew ${ }^{1}$, Meena Chandran², Geetha Elias ${ }^{3}$, Swathy P S \\ K Krishnakumar ${ }^{5}$
}

\author{
${ }^{1,4}$ M. Pharm Student, ${ }^{2}$ Associate Professor, ${ }^{5}$ Principal, \\ Department of Pharmaceutical Chemistry, St James College of Pharmaceutical Sciences and St James Hospital \\ Trust Pharmaceutical Research Centre (DSIR Recognized), Chalakudy, Kerala, India. Pin code- 680307 \\ ${ }^{3}$ Associate Professor, Department of Pharmaceutical Chemistry, Nirmala College of Health Science, Chalakudy, \\ Kerala, India. Pin code- 680307
}

Corresponding Author: Meena Chandran

\begin{abstract}
In step with the development of organic chemistry, heterocyclic compounds play an important part. Electron-rich nitrogen containing heterocyclic compounds and their derivatives play key role in diverse biological activities. The wide-ranging functionality and stereochemical complexity in a five-member ring structure is shown by the pyrazole nucleus, which has two nitrogen atoms and exhibit aromatic character. The medicinal chemists have been using the relationship between chemical structure and biological activity of a molecule in drug discovery as the driving force to guide synthetic efforts, to design new chemical derivatives. It has been reported that pyrazoline derivatives possess a broad spectrum of biological activities such as antibacterial, antimicrobial, anti-inflammatory, antioxidant, antidiabetic, anticancer, antifungal, antitubercular, antidepressant, anticonvulsant and analgesic activities. They also possess some potent receptor selective biological activities like monoamine oxidases (MAOs) inhibitor, Nitric oxide synthase (NOS) inhibitor, Angiotensin converting enzyme (ACE) inhibitor, cholecystokinin-1 receptor antagonist and estrogen receptor (ER) ligand activity. Hence in this article, we focus on the pyrazole derivatives having heteroaryl substituents and their pharmacological activities along with their structure-activity relationships in order to create
\end{abstract}

opportunities to explore the full potential of these compounds.

Keywords: Heterocyclic compounds, Pyrazolines, Claisen-Schmidt condensation, Chalcone.

\section{INTRODUCTION}

Heterocycles are an amazingly significant and matchless category of compounds; that make up more than half of all known organic compounds. Heterocycles are extensively distributed in nature and play a crucial role in metabolism because their structural subunits are present in many natural products, including vitamins, hormones, antibiotics, and alkaloids as well as pharmaceuticals, agrochemicals, dyes, and many others. [1] Heterocyclic compounds are exceptionally important for the design of active molecules. Biological molecules such as DNA and RNA also have heterocyclic ring in their main skeleton. These rings interact with enzymes or receptors without difficulty as they have capability to behave as hydrogen bond acceptors and donors. ${ }^{[2]}$

Amid heterocyclic compounds, nitrogen-containing heterocycles are the central part of several biologically active compounds and expose various applications in chemistry, biology and other sciences. 
Traditionally, nitrogen-containing heterocyclic compounds and their derivatives are a major source of therapeutic agents. [1] Pyrazole is one among the heterocyclic compound and is a fivemembered ring structure composed of three carbon atoms and two nitrogen atoms in adjacent positions. Pyrazole is represented by the molecular formula $\mathrm{C}_{3} \mathrm{H}_{4} \mathrm{~N}_{2}$ and it's a weak base. ${ }^{[3]}$ Pyrazolines, are also referred to as dihydropyrazoles. Depending on the site of endocyclic double bond there are three types of pyrazolines exist; 1pyrazolines, 2-pyrazolines and 3pyrazolines. ${ }^{[4]}$
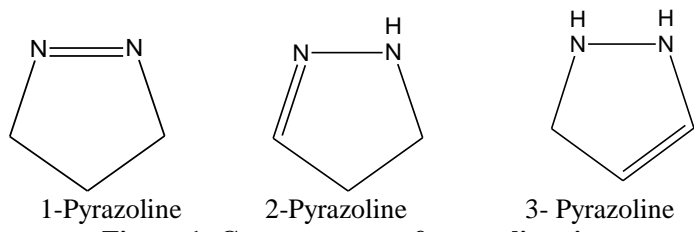

Figure 1: Core structure of pyrazoline ring

The electron rich nitrogen is the important component of Pyrazoline derivatives which contribute significantly to diverse biological activities. N-N bond linkage of the pyrazoline ring is regarded as the core factor in their biological activities. Living organisms set up these bonds with difficulty; consequently $\mathrm{N}-\mathrm{N}$ bonds are rarely found in natural compounds. Various drug molecules containing pyrazole and pyrazoline ring with different activities are currently available in the market such as antipyrine, ramifenazone, morazone, celecoxib, fezolamine and tepoxalin. ${ }^{[5]}$

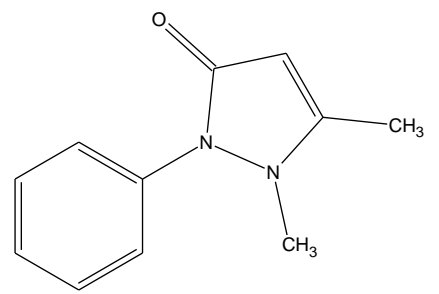

Antipyrine

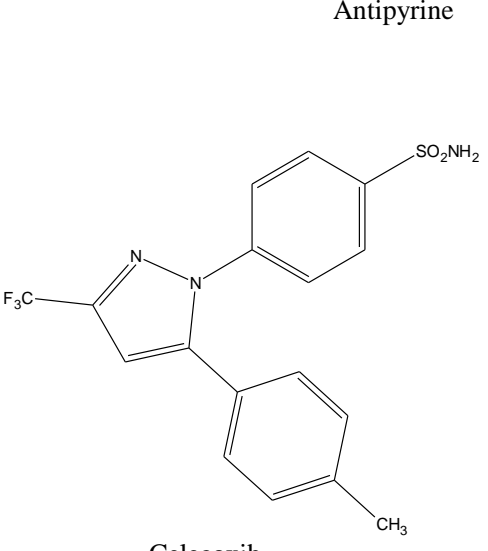

Celecoxib

Fezolamine

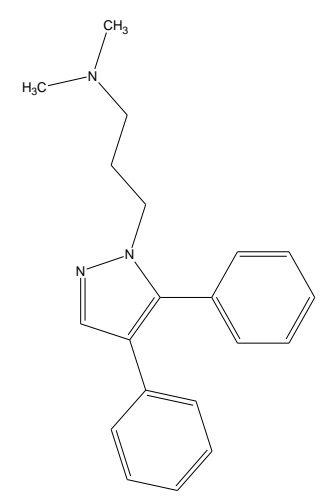

molecule containing pyrazole and pyrazoline rings
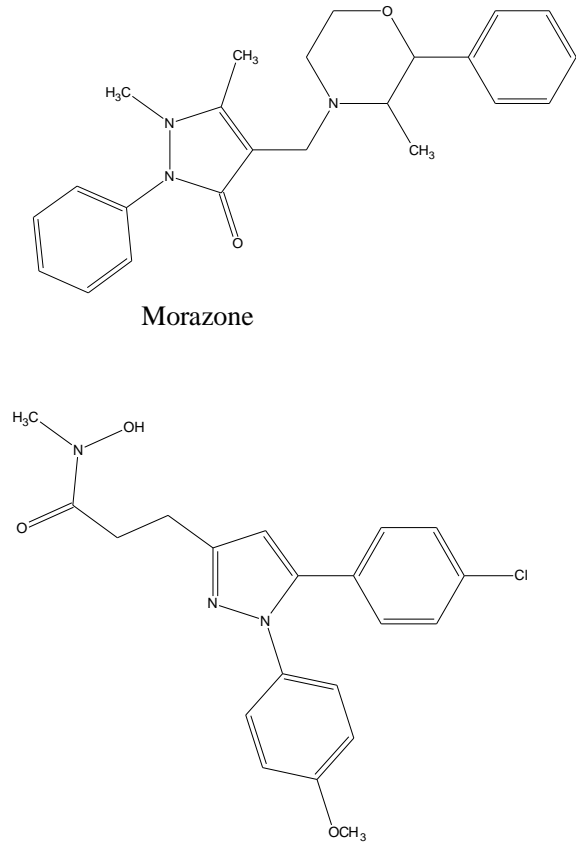

Tepoxalin

azoline rings available in the market
PHARMACOLOGICAL ACTIVITIES AND SAR STUDIES OF HETEROARYL SUBSTITUTED PYRAZOLINES:

Fatih Tok et al., (2020) have reported new 2-pyrazoline derivatives as potential anticancer agents. The derivatives were synthesized in three steps. In the first step 4-aminoacetophenone and different benzoyl chloride in chloroform reacted to form amide derivatives. Then, according to Claisen-Schmidt condensation new chalcone derivatives were prepared by N-(4acetylphenyl)-4-substituted benzamide with 
different aromatic aldehydes in aqueous ethanolic potassium hydroxide. New pyrazoline derivatives were obtained from chalcones and phenylhydrazine hydrochloride in acetic acid.

The synthesized new chalcone and pyrazoline derivatives which exhibited cytotoxic activities against HeLa, MCF7,
MKN-45 cancer cell lines and NIH-3T3 normal cell. The study reported that compounds $2 \mathrm{f}, 2 \mathrm{l}$ and 2 s contain pyrazoline ring as well as furan ring demonstrated strong cytotoxic effect on cancer cells. Moreover the compounds 2f, $2 \mathrm{l}$ and $2 \mathrm{~s}$ showed higher activity than chalcone analogs such as $1 \mathrm{f}, 11$ and $1 \mathrm{~s} .{ }^{[2]}$

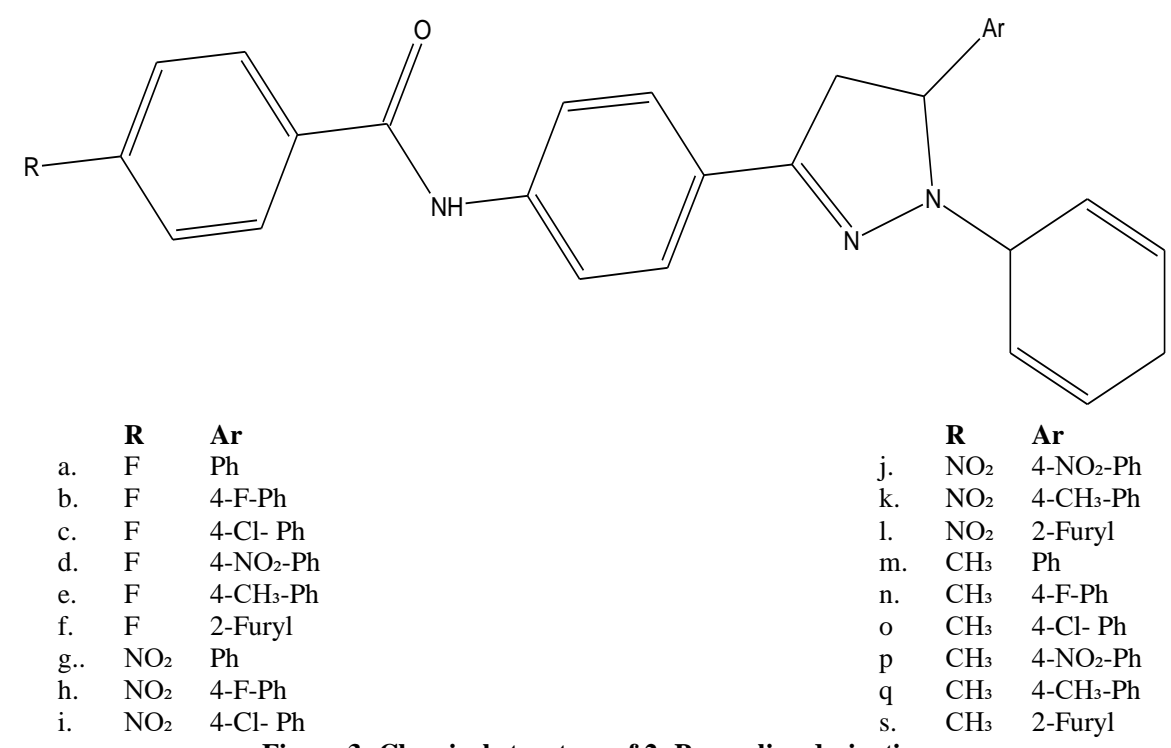

Figure 3: Chemical structure of 2- Pyrazoline derivatives

Farah Nawaz et al., (2020) have synthesized pyrazoline-linked carboxamide derivatives and evaluated for potential epidermal growth factor receptor (EGFR) kinase inhibition, anticancer activity, and apoptotic and cardiomyopathy toxicity. A reagent-based approach for pyrazoline synthesis coupled with carboxamide derivatives was used to construct the target derivatives $6 \mathrm{a}-0$. The compounds $6 \mathrm{~m}$ and 6n inhibit EGFR among all the synthesized compounds. The good broad- spectrum in vitro anticancer activity against the A549 and HCT-116 cancer cell line is exhibited by the compounds $6 \mathrm{~m}$ and $6 \mathrm{n}$ which are arrayed with 3-pyridine and the 4-pyridine group. Moreover, compounds $6 \mathrm{~m}$ and $6 \mathrm{n}$ were shown to induce apoptosis in A549 cancer cells. Molecular docking analysis of these compounds (6m and $6 \mathrm{n}$ ) explained its binding pattern features to be that of the drug EGFR inhibitor (erlotinib). On the other hand, cardiomyopathy studies showed normal cardiomyocytes with no marked sign of pyknotic nucleus of compound $6 \mathrm{n}$.

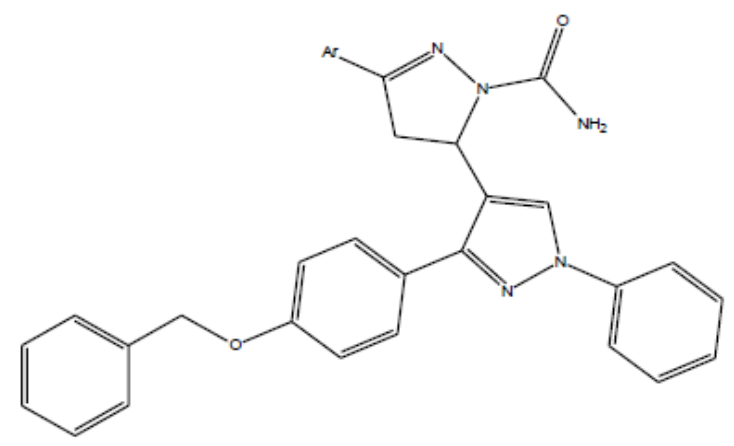




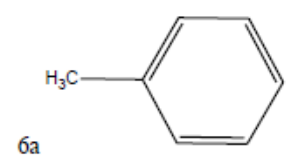

6a

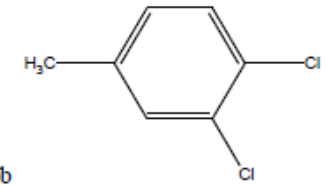

$6 \mathrm{~b}$

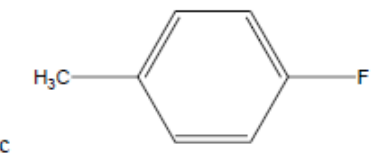

$6 \mathrm{~d}$

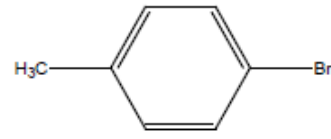

$6 f$

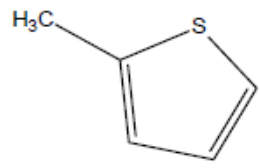

$6 \mathrm{~g}$

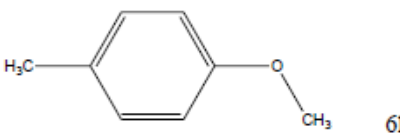

$6 \mathrm{~h}$

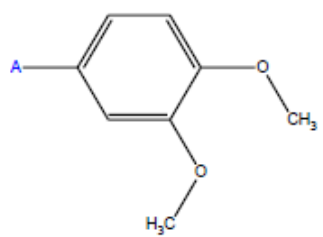

$6 \mathrm{i}$

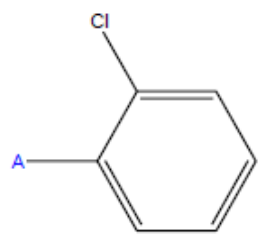

$6 \mathrm{j}$
$6 \mathrm{k}$

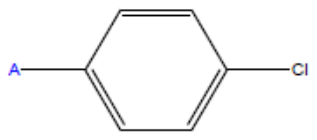

61

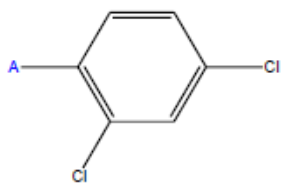

$6 \mathrm{~m}$

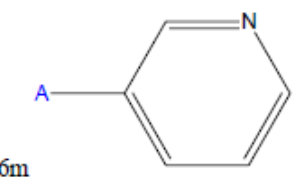

in

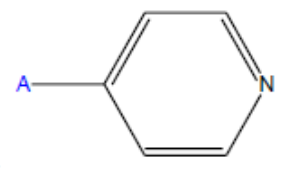

60

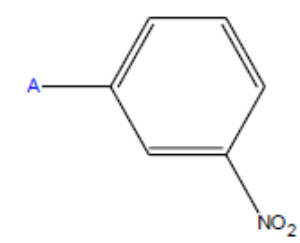

Figure 4: Structure of pyrazoline-linked carboxamide derivatives

While comparing with compounds that contain the electron-withdrawing group $(\mathrm{Cl}, \mathrm{Br}, \mathrm{F})$ and the compounds containing the heterocyclic group (4-pyridine, 3-pyridine, thiophene), the synthesized compound that consist of heterocyclic group had better antitumor activity as they were more intense in increasing EGFR kinase inhibitory activity. The compound $6 f$ (thiophene) when compared with compound 6n (4-pyridine) the activity increases with the increasing electronegativity of the atom on the heterocyclic ring. Also, among the electron-releasing series compounds containing the hydroxyl group on the para position of the phenyl ring (6e, 4-hydroxyphenyl) were found moderately active and the phenyl ring having methoxy group at the para position (6g, 4-methoxyphenyl) showed less activity. Introduction of the reagents having increased electronegativity as that in compound 4-fluorophenyl (6c) showed enhanced results rather than the addition of electron-withdrawing substituents (3,4-dichlorophenyl (6b), 4-bromophenyl $(6 \mathrm{~d})) .{ }^{[6]}$

\section{Amal Mahmoud Youssef} Moustafa., (2019) have discussed the design, synthesis and in vitro anti cancer activity of some novel pyrazole derivatives and pyrazoles containing thiazole moiety. Ethyl $\beta$-(p-chlorophenyl)- $\alpha$-cyanoacrylate and thiosemicarbazide materials was used as starting materials. Pyrazole derivatives containing thiazole moiety were synthesized via cyclization of pyrazole derivative with bromomethyl arylketones, followed by acetylation. The cytotoxic activity of all the synthetic compounds were evaluated against Leukemia HL-60 and Doxorubicin was used as the standard. Against Leukemia HL-60 cell line pyrazole derivatives containing thiazole moiety were the most active. ${ }^{[7]}$ 

and SAR studies.

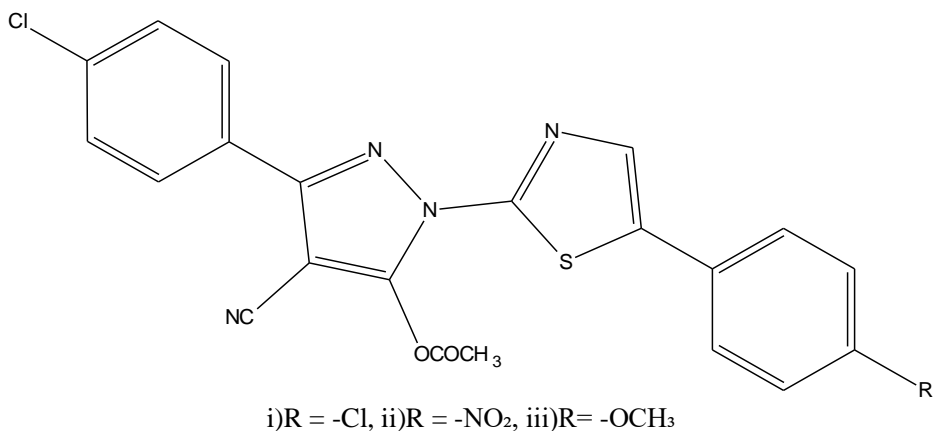

Figure 5: Pyrazole derivatives and pyrazole containing thiazole moiety

Mahadev N. Kumbar et.al., (2018) synthesized a series of novel 5-(1-aryl-3(thiophen-2-yl)-1H-pyrazol-4-yl)-1Htetrazoles 7(h-s). In this study the structures of synthesized compounds were docked into active site of COX-2 enzyme. The compounds $7 \mathrm{k}, 7 \mathrm{~m}, 7 \mathrm{n}$, and $7 \mathrm{q}-\mathrm{s}$ have reported excellent anti-inflammatory activity and compounds $7 \mathrm{i}, 7 \mathrm{k}, 71,7 \mathrm{n}$, and $7 \mathrm{~s}$ have exhibited anti-bacterial inhibitory potency in enzyme based assays.

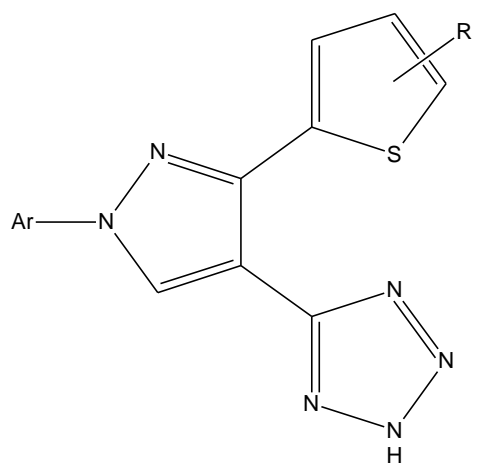

7h - 5-(1-Phenyl-3-(thiophen-2-yl)-1H-pyrazol-4-yl)-1H-tetrazole

$7 \mathrm{i}$ - 5-(1-(4-Bromophenyl)-3-(thiophen-2-yl)-1H-pyrazol-4-yl)- $1 \mathrm{H}$-tetrazole

$7 \mathrm{j}$ - 5-(1-(4-Chlorophenyl)-3-(thiophen-2-yl)-1H-pyrazol-4-yl)- 1H-tetrazole

7k - 5-(3-(5-Chlorothiophen-2-yl)-1-phenyl-1H-pyrazol-4-yl)- 1H-tetrazole

71 - 5-(1-(4-Bromophenyl)-3-(5-chlorothiophen-2-yl)-1H-pyrazol-4-yl)-1H-tetrazole

7m-5-(1-(4-Chlorophenyl)-3-(5-chlorothiophen-2-yl)-1H-pyrazol-4-yl)-1H-tetrazole

7n - 5-(3-(5-Bromothiophen-2-yl)-1-phenyl-1H-pyrazol-4-yl)- 1H-tetrazole

Figure 6: A series of 5-(1-aryl-3-(thiophen-2-yl)-1H-pyrazol-4-yl)-1H-tetrazoles

From the structure-activity relationships study it showed that 2methoxythiophene with pyrazole-tetrazole derivatives have the selective inhibition of the COX-2 isoenzyme and exhibited excellent anti-inflammatory activities. While compared with the standard drug Celecoxib, the compounds $7 \mathrm{~m}$ and $7 \mathrm{n}$ exhibited potent anti-inflammatory activity. The obtained results revealed that compounds derived from thiophenes along with pyrazoles exhibited better antiinflammatory and antibacterial activity than their tetrazole structure variants. ${ }^{[8]}$

S. Salman Ahmad Khan et al., (2014) under microwave irradiation various pyrazoline and pyrimidine derivatives were synthesized by the reaction of thiosemicarbazide / phenyl hydrazine/ hydrazinehydrate/ thiourea/ urea with 3-(3,4-dimethoxy-phenyl- 1-(2,5-dimethylthiophen-3-yl)-propenone, which itself was derived from the reaction of 3-acetyl-2,5-dimethylthiophene with 3,4dimethoxy benzaldehyde. By using the disk diffusion assay method the anti-bacterial activity of these compounds were tested in-vitro against two Gram-positive and two Gram-negative bacteria. The results showed that the first two compounds showed better at inhibiting the growth of both types of the bacteria (Gram- positive and Gram-negative) as compared to chloramphenicol. [9] 


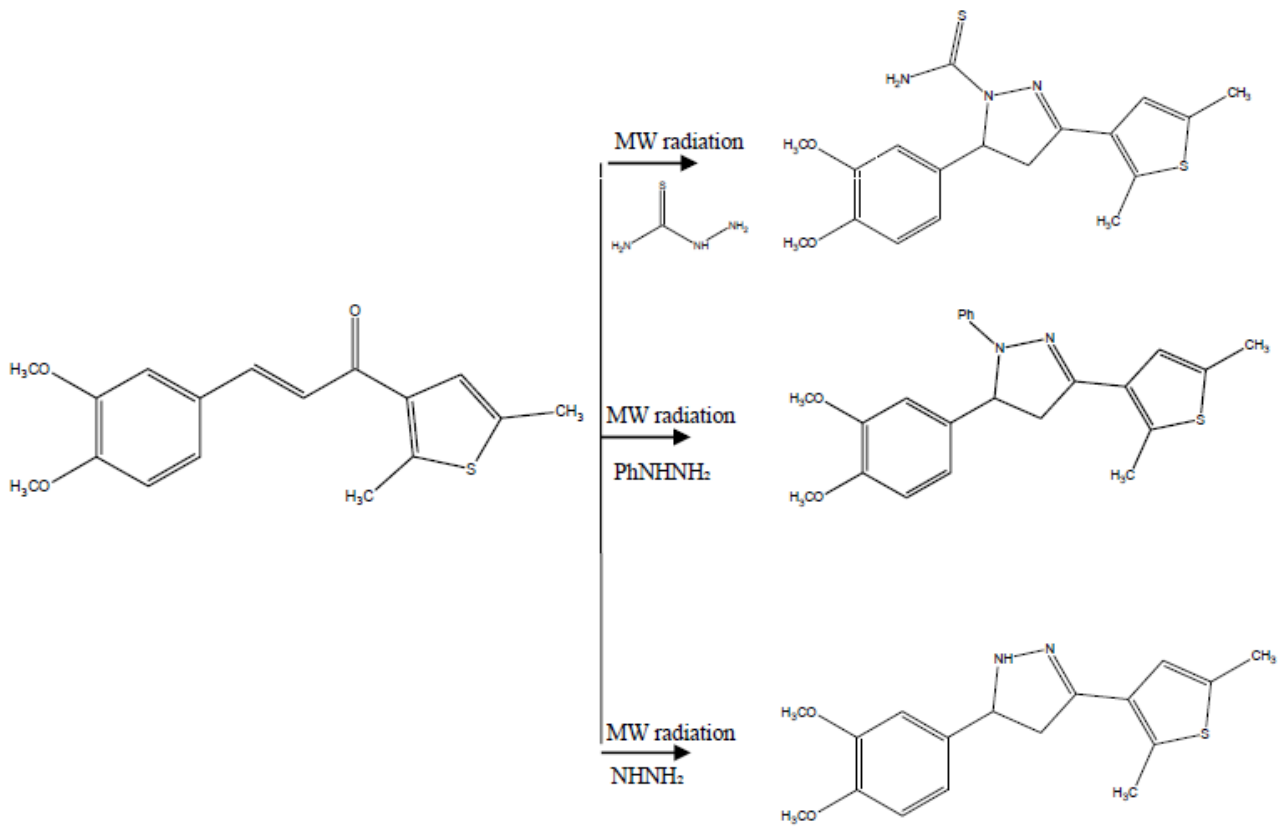

Figure 7: Structures of pyrazoline derivatives from 3-(3,4-dimethoxy-phenyl- 1-(2,5-dimethyl- thiophen-3-yl)-propenone

Bijo Mathew et al., (2014) synthesized a series of phenyl-3-(thiophen2-yl)-4,5-dihydro-1H-pyrazole-1carbothioamides (TTa-TTg) and evaluated for their antidepressant and neurotoxicity screening. The pyrazoline derivatives were synthesized using the ring closure reaction of phenyl-1-(thiophen-2-yl) prop-2-en-1ones with thiosemicarbazide in alcoholic basic medium.

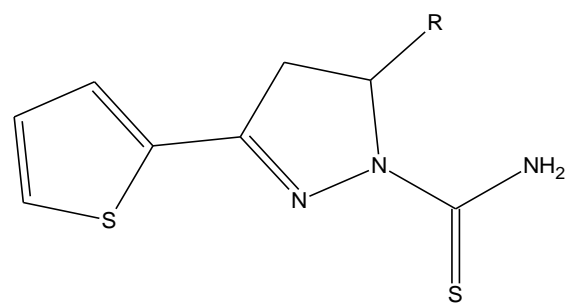

$$
\begin{aligned}
& \text { TTa - phenyl } \\
& \text { TTb - 4-chloro phenyl } \\
& \text { TTc }-4 \text {-methoxy phenyl } \\
& \text { TTd - 4N,N dimethyl phenyl } \\
& \text { TTe - 3-nitro phenyl } \\
& \text { TTf - 2-hydroxy phenyl } \\
& \text { TTg - 4-hydroxy phenyl }
\end{aligned}
$$

Figure 8: Series of phenyl-3-(thiophen-2-yl)-4, 5-dihydro-1H-pyrazole-1-carbothioamides (TTa-TTg)

The good antidepressant activity was reported by the derivatives posseing electron withdrawing chlorine atom in the $4^{\text {th }}$ position of aromatic ring. The examination revealed that pyrazoline derivatives containing thiophene with a carbothioamide tail unit in the $\mathrm{N}_{1}$ position may therapeutically valuable as promising antidepressant medications. ${ }^{[10]}$

Ahmet O" zdemir et al., (2013) have synthesized and reported antimicrobial activity for pyrazoline derivatives bearing an indole moiety. 1-(p-Methylphenyl)-3,5diaryl-2-pyrazoline derivatives $(2 \mathrm{a}-\mathrm{f})$ were synthesized by 1-(1H-indol-3-yl)-3-aryl-2propen-1-ones (1a-f) with pmethylphenylhydrazine hydrochloride treated with hot acetic acid. Compound 2e, a pyrazoline derivative consisting the 2,5dichlorophenyl moiety, recognized as the most potential agent against Klebsiella pneumoniae (ATCC 13883) and Candida glabrata (ATCC 36583). ${ }^{[11]}$

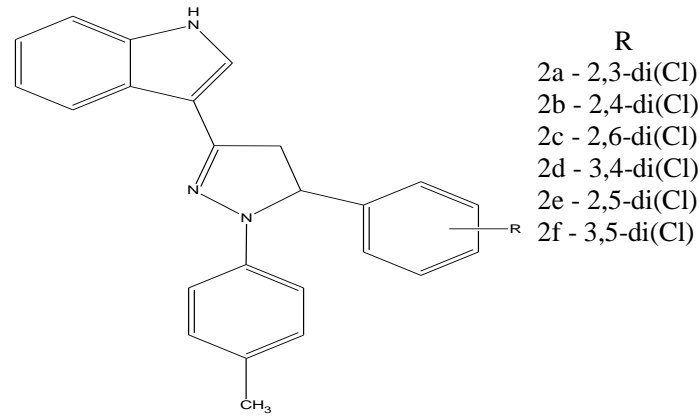

Figure 9: Structure of pyrazoline derivatives bearing an indole moiety

Nagihan Beyhana et al., (2013) have synthesized 2-pyrazoline derivatives 

and SAR studies.

2a-i and 3a-e by the reaction of chalcones with thiosemicarbazide and N-(4chlorophenyl)semicarbazide. 2-Pyrazoline derivatives synthesized were screened for

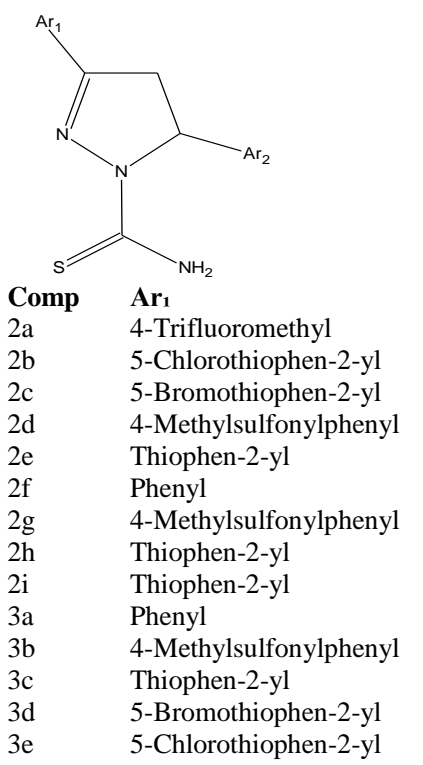

Figure 10: Structure of pyrazoline derivatives with thiosemicarbazide and $\mathrm{N}$-(4-chlorophenyl) semicarbazide

2-pyrazoline-1-carboxamide derivatives carrying 5-bromothiophen, 5chlorothiophen and 2, 6-dichlorophenyl groups exhibited remarkable activity in PTZ test among the tested compounds for the anticonvulsant screening test. ${ }^{[12]}$

Bahman Sharifzadeh et al., (2013) have synthesized via a three-component reaction a novel bioactive thiazolylpyrazoline derivatives and examined their antimicrobial activity. A three-component cyclo-condensation of various chalcones, thiosemicarbazide and phenacyl bromide were used for the synthesis of series of novel 2-(3,5-diphenyl-4,5-dihydro-1Hpyrazol-1-yl)-4-phenylthiazoles . The study states that the easy work-up of the products, their potential anticonvulsant activity in pentylene tetrazole induced seizure (PTZ) and maximal electroshock seizure (MES) tests.

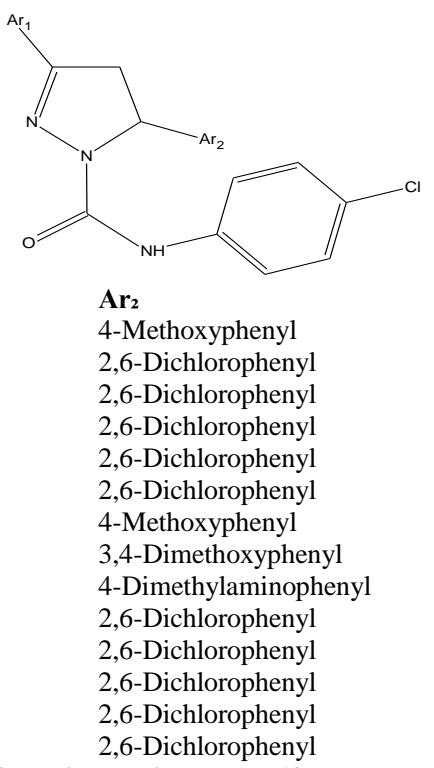

rapid reaction, and mild conditions were the distinguished features of this procedure. The reaction provides a moderate to high yields while the reagents were catalyzed in one-pot by a few drops of $\mathrm{HCl}$ in $\mathrm{EtOH}$ under reflux conditions. Due to the incorporation of thiophene ring (6c and 6d) and electrondonating groups like $-\mathrm{OCH}_{3}$ and $-\mathrm{CH}_{3}(6 \mathrm{f}-$ i) compounds $6 \mathrm{c}, 6 \mathrm{~d}$ and $6 \mathrm{f}-\mathrm{i}$ exhibited superior antibacterial activity against Pseudomonas aeruginosa. The compounds $6 \mathrm{~b}, 6 \mathrm{c}, 6 \mathrm{f}, 6 \mathrm{~h}$ and $6 \mathrm{i}$ have moderate growthinhibiting activity against Escherichia coli. Also 6a, 6d, 6e, 6g and 6h show moderate growth-inhibiting Staphylococcus aureus. activity on

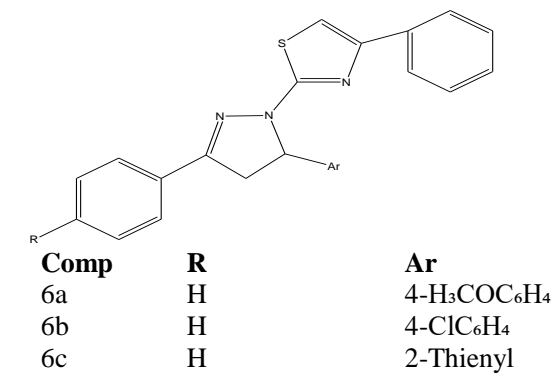



and SAR studies.

Simone Carradori et al., (2012) have synthesized novel 1-(4-substitutedthiazol-2-yl)-3,5-di(hetero)aryl-pyrazoline derivatives and investigated the ability to selective inhibitory activity against human COX-1. 3,5-di(hetero)aryl-1-thiocarbamoyl2-pyrazolines with the ethyl ester of a bromo-pyruvic acid were used for the synthesis of 2-pyrazoline derivatives. In the micromolar range the derivatives (compounds 5, 6, 13, 16, and 17) exhibited promising selectivity against hCOX-1 and were shown to have a selectivity index similar or better than the reference drugs (indomethacin, diclofenac). They reported that the activity against hCOX-1 was improved by the introduction of a phenyl or a 4-F-phenyl ring on the $\mathrm{C} 5$ linked with a 4-substituted phenyl or a heteroaryl group on the C3 of (4-substituted-thiazol-2yl)pyrazoline derivatives. ${ }^{[14]}$

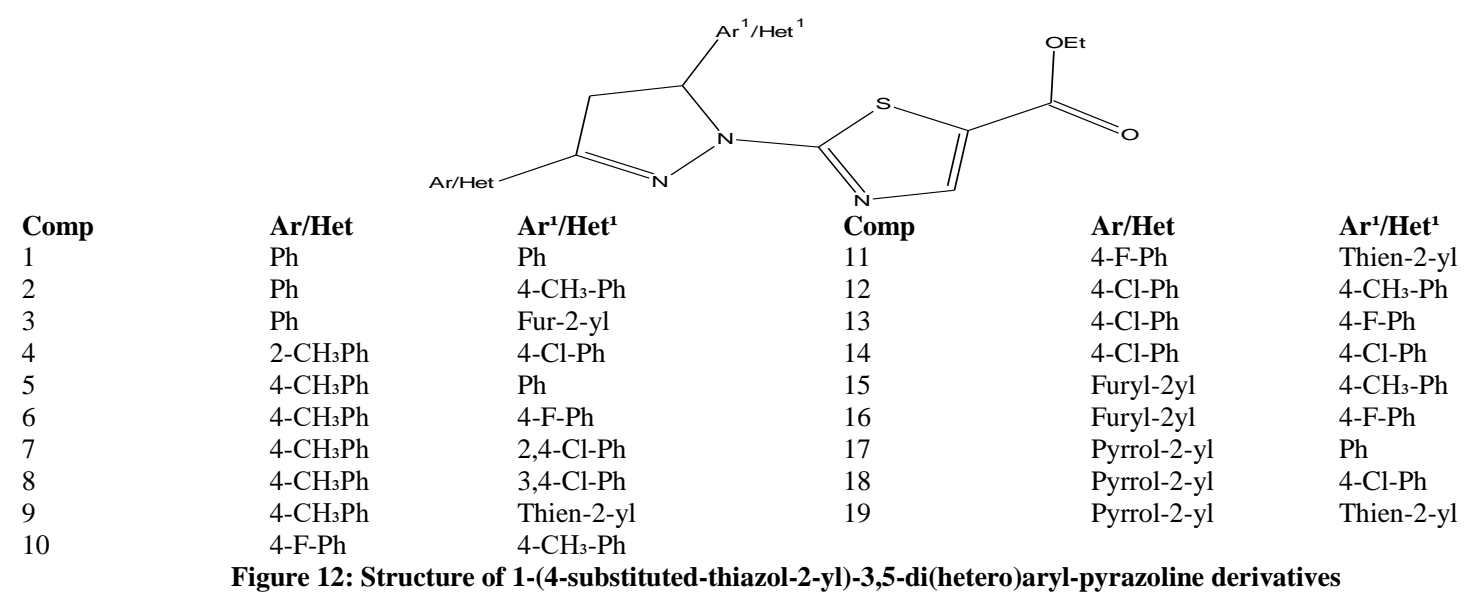

Hui Deng et al., (2012) the introduction of furan rings into the scaffold of pyrazolines generate a series of structurally related 1,3,5-trisubstituted-2pyrazoline derivatives which is regarded as bioactive substructure and tested for their activities against six plant pathogenic fungi in vitro. Compounds $4,7,9,12,18,19$, and
38 provided exceptional antifungal activities against Rhizoctonia solani and at the concentration of $20 \mathrm{mg} / \mathrm{L}$ their inhibition of growth reached $100 \%$. Furthermore, compounds 9 and 19 bearing two furan rings, respectively, at site 3 and site 5 of the pyrazoline cycle showed the strongest activities against $R$. solani. ${ }^{[15]}$

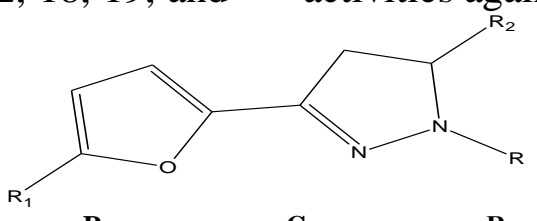

$\begin{array}{ll}\mathbf{R}_{2} & \mathbf{R} \\ 3-\mathrm{NO}_{2} \mathrm{Ph} & -\mathrm{C}(\mathrm{O}) \mathrm{CH}_{3}\end{array}$

$2-\mathrm{NO}_{2} \mathrm{Ph}$

$4-\mathrm{Br}-\mathrm{Ph}$

4-Cl-Ph

2-Cl-Ph

$3,4-\mathrm{Cl}_{2}-\mathrm{Ph}$

2,4- $\mathrm{Cl}_{2}-\mathrm{Ph}$

4- $\mathrm{OCH}_{3} \mathrm{Ph}$

2-Furyl

$4-\mathrm{NO}_{2} \mathrm{Ph}$

2-Cl-Ph

4-Cl-Ph

2,4- $\mathrm{Cl}_{2}-\mathrm{Ph}$

4-Br-Ph

3-F-Ph

4-F-Ph

4- $\mathrm{OCH}_{3} \mathrm{Ph}$

Phenyl

2-Furyl
$-\mathrm{C}(\mathrm{O}) \mathrm{CH}_{3} \quad 20$

$-\mathrm{C}(\mathrm{O}) \mathrm{CH}_{3}$

$-\mathrm{C}(\mathrm{O}) \mathrm{CH}_{3}$

$-\mathrm{C}(\mathrm{O}) \mathrm{CH}_{3}$

$-\mathrm{C}(\mathrm{O}) \mathrm{CH}_{3}$

$-\mathrm{C}(\mathrm{O}) \mathrm{CH}_{3}$

$-\mathrm{C}(\mathrm{O}) \mathrm{CH}_{3}$

$-\mathrm{C}(\mathrm{O}) \mathrm{CH}_{3}$

$-\mathrm{C}(\mathrm{O}) \mathrm{CH}_{3}$

$-\mathrm{C}(\mathrm{O}) \mathrm{CH}_{3}$

$-\mathrm{C}(\mathrm{O}) \mathrm{CH}_{3}$

$-\mathrm{C}(\mathrm{O}) \mathrm{CH}_{3}$

$-\mathrm{C}(\mathrm{O}) \mathrm{CH}_{3}$

$-\mathrm{C}(\mathrm{O}) \mathrm{CH}_{3}$

$-\mathrm{C}(\mathrm{O}) \mathrm{CH}_{3}$

$-\mathrm{C}(\mathrm{O}) \mathrm{CH}_{3}$

$-\mathrm{C}(\mathrm{O}) \mathrm{CH}_{3}$

$-\mathrm{C}(\mathrm{O}) \mathrm{CH}_{3}$
$\mathbf{R}_{1}$

$\mathrm{H}$

$\mathrm{H}$
$\mathrm{H}$

$\mathrm{H}$

$\mathrm{H}$

$\mathrm{H}$

$\mathrm{H}$

H

$\mathrm{CH}_{3}$

$\mathrm{CH}_{3}$

$\mathrm{CH}_{3}$

$\mathrm{CH}_{3}$

$\mathrm{CH}_{3}$

$\mathrm{CH}_{3}$

$\mathrm{CH}_{3}$

$\mathrm{CH}_{3}$

$\mathrm{CH}_{3}$

$\mathrm{CH}_{3}$
$\mathbf{R}_{2}$

$3-\mathrm{NO}_{2} \mathrm{Ph}$

$2-\mathrm{NO}_{2} \mathrm{Ph}$

4-Br-Ph

4-Cl-Ph

2-Cl-Ph

3,4- $\mathrm{Cl}_{2}-\mathrm{Ph}$

$2,4-\mathrm{Cl}_{2}-\mathrm{Ph}$

4- $\mathrm{OCH}_{3} \mathrm{Ph}$

2-Furyl

4- $\mathrm{NO}_{2} \mathrm{Ph}$

2-Cl-Ph

4-Cl-Ph

2,4- $\mathrm{Cl}_{2}-\mathrm{Ph}$

4-Br-Ph

3-F-Ph

4-F-Ph

$4-\mathrm{OCH}_{3} \mathrm{Ph}$

Phenyl

2-Furyl
$\mathbf{R}$

Phenyl

Phenyl

Phenyl

Phenyl

Phenyl

Phenyl

Phenyl

Phenyl

Phenyl

Phenyl

Phenyl

Phenyl

Phenyl

Phenyl

Phenyl

Phenyl

Phenyl

Phenyl 

and SAR studies.

S. Sridhar et al., (2012) have synthesized different chalcones by the reaction of 3-acetyl-2,5- dimethylfuran and various substituted aromatic and hetero cyclic aldehydes. The reaction carried out in presence of aqueous potassium hydroxide and ethanol. Then by the reaction of chalcones with phenylhydrazine in presence of hot pyridine, good yields of pyrazolines were obtained. The synthesized compounds were determined for their analgesic activity.

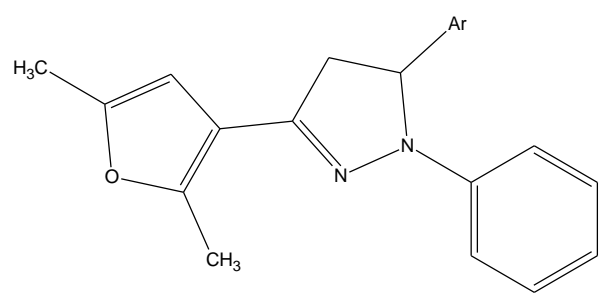

$$
\begin{aligned}
& \begin{array}{ll}
\text { Comp } & \text { Ar } \\
\text { 4a } & 4 " \text {-methoxyphenyl }
\end{array} \\
& \begin{array}{l}
\text { 4a 4"'-methoxyphenyl } \\
4 \mathrm{~b} \\
\text { 3', } 4 \text { ''-dimethoxyphenyl }
\end{array} \\
& 4 c \quad 4 \text { "-fluorophenyl } \\
& \text { 4d 4"-nitrophenyl } \\
& \text { 4e 2"-thienyl } \\
& \text { 4f 3', 4', } 5 \text {,'-trimethoxyphenyl } \\
& 4 \mathrm{~g} \quad 4 \text { "'-chlorophenyl } \\
& \text { 4h 4"-methylphenyl } \\
& 4 \mathrm{i} 9 \text { "'-anthryl } \\
& 4 j \quad 2 \text { "',4"-dichlorophenyl }
\end{aligned}
$$

Figure 14: Structure of pyrazoline derivatives from 3-acetyl2,5- dimethylfuran

They reported that the compound $4 \mathrm{f}$ and 4a having 3, 4, 5- trimethoxyphenyl and 4-methoxyphenyl ring at the 5-position of the 2- pyrazoline ring respectively possessed the maximum activity. Thus, it indicates that the analgesic activity of the 2pyrazolines is due to the favorable effect of electron releasing substituents. ${ }^{[16]}$

\section{CONCLUSION}

There is considerable evidence that pyrazole and its derivatives have potential for design of novel drugs. In this review, from the structure activity relationship studies of heteroaryl substituted pyrazolines, we infer that these moieties have exhibited diverse biological activities such as antimicrobial, anti-inflammatory, antioxidant, anticancer, antifungal, antidepressant, anticonvulsant, and analgesic activities. Among all other substituents heteroaryl compounds such as
2- furyl that attached to the pyrazoline moiety exhibited strong cytotoxic effect on cancer cells (Leukemia HL- 60) and also thiophene attached to pyrazolines showed better anti-inflammatory and anti- bacterial activity than the other aromatic substituted compounds. Hence these data may be useful for future molecular modifications leading to compounds with superior pharmacological activities having heteroaryl substitution in the pyrazoline nucleus.

\section{Acknowledgement: None}

\section{Conflict of Interest: None}

\section{Source of Funding: None}

\section{REFERENCES}

1. Ansari A, Ali A, Asif M. Biologically active pyrazole derivatives. New Journal of Chemistry. 2017; 41(1):16-41.

2. Tok F, Abas Bİ, Çevik Ö, KoçyiğitKaymakçığlu B. Design, synthesis and biological evaluation of some new 2Pyrazoline derivatives as potential anticancer agents. Bioorganic Chemistry. 2020 Sep 1; 102:104063.

3. Alam O, Naim M, Nawaz F, Alam M, Alam P. Current status of pyrazole and its biological activities. Journal of Pharmacy and Bioallied Sciences. 2016; 8(1):2.

4. Yusuf M, Jain P. Synthetic and biological studies of pyrazolines and related heterocyclic compounds. Arabian Journal of Chemistry. 2014; 7(5):553-596.

5. Matiadis D, Sagnou M. Pyrazoline Hybrids as Promising Anticancer Agents: An Up-toDate Overview. International Journal of Molecular Sciences. 2020; 21(15):5507.

6. Nawaz F, Alam O, Perwez A, Rizvi MA, Naim MJ, Siddiqui N, Pottoo FH, Jha M. 3'-(4-(Benzyloxy) phenyl)-1'-phenyl-5-(heteroaryl/aryl)-3, 4-dihydro-1' $\mathrm{H}, \quad 2 \mathrm{H}-[3$, 4'-bipyrazole]-2-carboxamides as EGFR kinase inhibitors: Synthesis, anticancer evaluation, and molecular docking studies. Archiv der Pharmazie. 2020 Apr; 353(4):1900262.

7. Moustafa AM. In vitro Anti Leukemia Cancer Activity of Some Novel Pyrazole Derivatives and Pyrazoles Containing 
Thiazole Moiety. American Journal of Heterocyclic Chemistry. 2019 Aug 14; 5(3):55-70.

8. Kumbar MN, Kamble RR, Dasappa JP, Bayannavar PK, Khamees HA, Mahendra M, Joshi SD, Dodamani S, Rasal VP, Jalalpure S. 5-(1-Aryl-3-(thiophen-2-yl)1H-pyrazol-4-yl)-1H-tetrazoles: Synthesis, structural characterization, Hirshfeld analysis, anti-inflammatory and antibacterial studies. Journal of Molecular Structure. 2018 May 15; 1160:63-72.

9. Khan SA, Asiri AM, Kumar S, Sharma K. Green synthesis, antibacterial activity and computational study of pyrazoline and pyrimidine derivatives from 3-(3, 4dimethoxy-phenyl-1-(2, 5-dimethylthiophen-3-yl)-propenone. European Journal of Chemistry. 2014 Mar 31; 5(1):85-90.

10. Mathew B, Suresh J, Anbazhagan S. Synthesis, preclinical evaluation and antidepressant activity of 5-substituted phenyl-3-(thiophen-2-yl)-4, 5-dihydro-1Hpyrazole-1-carbothioamides.

EXCLI journal. 2014; 13:437.

11. Özdemir A, Altintop MD, Kaplancıklı ZA, Turan-Zitouni G, Karaca H, Tunali Y. Synthesis and biological evaluation of pyrazoline derivatives bearing an indole moiety as new antimicrobial agents. Archiv der Pharmazie. 2013 Jun; 346(6):463-9.

12. Beyhan N, Kocyigit-Kaymakcioglu B, Gümrü S, Aricioglu F. Synthesis and anticonvulsant activity of some 2pyrazolines derived from chalcones.
Arabian Journal of Chemistry. 2013 May 1; 10:S2073-81.

13. Sharifzadeh B, Mahmoodi NO, Mamaghani M, Tabatabaeian K, Chirani AS, Nikokar I. Facile regioselective synthesis of novel bioactive thiazolyl-pyrazoline derivatives via a three-component reaction and their antimicrobial activity. Bioorganic \& medicinal chemistry letters. 2013 Jan 15; 23(2):548-51.

14. Carradori S, Secci D, Bolasco A, De Monte C, Yanez M. Synthesis and Selective Inhibitory Activity Against Human COX-1 of Novel 1-(4-Substituted-thiazol-2-yl)-3, 5-di (hetero) aryl-pyrazoline Derivatives. Archiv der Pharmazie. 2012 Dec; 345(12):973-9.

15. Deng H, Yu ZY, Shi GY, Chen MJ, Tao K, Hou TP. Synthesis and In Vitro Antifungal Evaluation of $1, \quad 3$, 5-Trisubstituted-2-Pyrazoline Derivatives. Chemical biology \& drug design. 2012 Mar; 79(3):279-89.

16. Sridhar S, Rajendraprasad Y. Synthesis and analgesic studies of some new 2pyrazolines. E-Journal of Chemistry. 2012 Jan 1; 9(4):1810-5.

How to cite this article: Mathew AT, Chandran $\mathrm{M}$, Elias $\mathrm{G}$ et.al. A review on heteroaryl substituted pyrazolines with their pharmacological activity and SAR studies. International Journal of Research and Review. 2021; 8(10): 174-183. DOI: https://doi.org/10. 52403/ijrr.20211022 